\section{The open field as a test of emotionality}

\section{DANIEL E. HENDRICKS and BILL SEAY Louisiana State University, Baton Rouge, Louisiana 70803}

According to Broadhurst (1969), the open field "has now reached the status of one of the few widely used, relatively standardized instruments in animal psychology." Although the open field is the most commonly used test of emotionality, a review of the literature indicates that neither the apparatus nor the test procedures have been standardized. Thus, the purpose of this study was to determine the effect of variations in the size and shape of the field apparatus on behavioral indicants of emotionality.

In order to examine the relative sensitivity of the fields to different levels of emotionality, half of the animals received 4 days' experience in Anderson's (1941) water wader. Watson (reported by Broadhurst, 1958) found that any previous experience reduced emotionality in the open field.

Since there have been numerous attacks on the validity of the open-field emotionality test (see Tobach \& Schneirla, 1962; Becker, 1969), it seems appropriate that the effects of manipulating characteristics of the field be evaluated.

\section{METHOD}

Subjects

Forty naive male albino rats from Louisiana State University's breeding colony were used.

\section{Apparatus}

Field A was circular with an 8-ft diam. Field B was a square with 8-ft sides. Field $C$ was circular with a diameter of 45 in. Field D was square with 45-in. sides. Each had sides 18 in. high, painted flat black. The floors were also painted flat black and were divided into 9-in. squares by thin white lines. The water wader (W) consisted of a metal container, 14 in. high and $10 \frac{1}{2}$ in. in diam, with $1 \frac{1 / 2}{2}$ in. of water. A 100 -W bulb was suspended 36 in. above the center of all apparatus.

\section{Procedure}

The animals, housed singly after 23 days of age, were tested between 65 and 77 days of age. Four groups of animals (A, B, C, and $D)$ received 4 days of testing in the field. The other four groups (WA, WB, WC, and WD) received 4 days of the $W$ test before being tested in the field. Each animal was placed in the appropriate apparatus for a 5 -min trial on 4 consecutive days. The fields were cleaned with a wet sponge mop and dried after every trial.

A modified frequency recording system was used; during each of 605 -sec intervals, an animal received a score of zero or one on all except three of the categories. For ambulation, total frequency of lines crossed was recorded; for defecation and micturation, the number of boluses or urinations per 5 -min trial constituted the score. The other behavioral categories and their scoring were as follows: (a) latency-the number of 5-sec intervals before a line was crossed, (b) resting freezing or no other behavior for $15 \mathrm{sec}$, (c) grooming-number of 5-sec intervals in which self-washing occurred, (d) jumping-number of $5-\sec$ intervals in which the animal leaped from the floor of the apparatus, (e) standing-the number of 5-sec intervals in which the animal stood upright on its rear legs, and (f) vocal distress-the number of 5-sec intervals in which a high-pitched vocalization occurred.

\section{RESULTS}

Analyses of variance on the effects of size and shape of the field indicated that grooming and resting occurred with different frequencies in the fields $(p<.05)$. Animals in Field D rested more than animals in Field A, and animals in Field B groomed significantly more than those in Fields $C$ and $D$. Previous testing in the $W$ increased both standing and grooming in the fields $(\mathrm{p}<.005)$.

There was a significant trials effect across fields for ambulation $(\mathrm{p}<.001)$; movement on the first day was significantly greater than the movement on each of the following 3 days. An examination of the trials by experience effect for movement $(p<.05)$ showed that for animals without any prior experience, the movement score was higher on Day 1 but lower on the following days than the score of experienced animals. The trials effect for resting was also significant $(\mathrm{p}<.001)$. Animals rested less on the first day than on the following 3 days. The significant Trials by Experience interaction $(p<.005)$ indicated that resting increased more across days for animals tested first in the field. On the first day in the field, animals in Field B groomed more than animals in the three other fields; in Field A, grooming on the fourth day was greater than that on the first day.

\section{DISCUSSION}

The results indicate that the use of several sizes and shapes of open fields affects the frequency of selected behaviors in the fields. A reduction of emotionality following prior experience in another fear-producing situation was reflected by two behavior categories. Grooming, a behavior that occurs during one-third to one-half of the animal's waking time (Bolles, 1960), was the only behavior sensitive to both the dimensions of the field and prior testing.

As Denenberg's (1969) factor analysis has partially confirmed, behavior on the first day of testing may be quantitatively dissimilar and have a different meaning than behavior on succeeding days. Ambulation, testing, grooming, and standing all showed differential behavior across days in accordance with this hypothesis.

\section{REFERENCES}

Anderson, E. E. Sex differences in timidity in normal and gonadectomized rats. Journal of Genetic Psychology, 1941, $59,139-153$

Becker, $G$. Initial and habituated autonomic reactivity in the male and female rat. Journal of Comparative \& Physiological Psychology, 1969,69, 459-464.

Bolles, R. C. Grooming behavior in the rat. Journal of Comparative \& Physiological Psychology, 1960, 53, 306-310.

Broadhurst, P. L. Determiners of emotionality in the rat. II. Antecedent factors. British Journal of Psychology, 1958, 49, 12-20.

Broadhurst, P. L. Psychogenics of emotionality in the rat. Annals of the New York Academy of Sciences, 1969, 159, 806-824.

Denenberg, V. H. Open-field behavior in the rat: What does it mean? Annals of the New York Academy of Sciences, 1969 , $159,852-859$

Tobach, E., \& Schneirla, T. C. Eliminative responses in mice and rats and the problem of "emotionality." In E. L. Bliss (Ed.), Roots of behavior. New York: Harper, 1962. Pp. 211-231.

(Received for publication August 24, 1972; revision received October $29,1972$. 